\title{
Using Temporal Analytics to Detect Inconsistencies between Learning Design and Student Behaviours
}

\author{
Quan Nguyen¹, Michal Huptych², Bart Rienties ${ }^{3}$
}

\begin{abstract}
Extensive research in learning science has established the importance of time management in online learning. Recently, learning analytics (LA) has shed further lights on the temporal characteristics of learning by allowing researchers to capture authentic digital footprints of student learning behaviours. Nonetheless, students' timing of engagement and its relation to learning design (LD) and academic performance have received limited attention. This study investigates to what extent students' timing of engagement aligned with instructor learning design, and how engagement varied across different levels of performance. Our findings revealed a mismatch between how instructors designed for learning and how students study. In most weeks, students spent less time studying the assigned materials on the virtual learning environment (VLE) compared to the number of hours recommended by instructors. The timing of engagement also varied, from in advance to catching up patterns. High-performing students spent more time studying in advance, while low-performing students spent a higher proportion of their time on catching-up activities. By incorporating the pedagogical context into learning analytics, not only we can understand what, why, and when students engage, but also how their behaviours are influenced by the way instructors design for learning.
\end{abstract}

\section{Notes for Practice}

- Students spent, on average, less time studying in the virtual learning environment (VLE) than the number of hours recommended by instructors.

- High-performing students not only studied harder (i.e., spent more time) but also smarter (i.e., spent more time studying in advance) than low-performing students.

- Linking learning design with learning analytics allows instructors to pinpoint specific study materials that were causing delays in the student learning process.

\section{Keywords}

Learning analytics, learning design, time management, temporal analysis, engagement.

Submitted: 18.06.2018 - Accepted: 30.08.2018 — Published: 11.12.2018

Corresponding author ${ }^{1}$ Email: quan.nguyen@open.ac.uk Address: Institute of Educational Technology, Open University, MK7 6AA, United Kingdom. ORCID: https://orcid.org/0000-0001-8937-5121

${ }^{2}$ Email: Michal.Huptych@cvut.cz Address: Czech Institute of Informatics, Robotics and Cybernetics, Jugoslávských partyzánů 1580/3, 160 00 Dejvice, Czech Republic. ORCID: https://orcid.org/0000-0001-8422-9694

${ }^{3}$ Email: bart.rienties@open.ac.uk Address: Institute of Educational Technology, Open University, MK7 6AA, United Kingdom. ORCID: https://orcid.org/0000-0003-3749-9629

\section{Introduction}

Recent years have witnessed an increased interest in leveraging learning analytics (LA) to inform and support learning design (LD; Lockyer, Heathcote, \& Dawson, 2013; Mor, Ferguson, \& Wasson, 2015; Persico \& Pozzi, 2015). One of the main benefits of aligning LA with LD is that LA could act as a reflective resource on how students actually behave compared to instructors' assumptions embedded in their LD, an observation that has been echoed by many scholars (Dalziel et al., 2016; Mor et al., 2015). Although substantial progress has been made within the LAK community to link how instructors' LD decisions with what students are doing (Bakharia et al., 2016; Lockyer et al., 2013; Nguyen, Rienties, \& Toetenel, 2017b; Rienties \& Toetenel, 2016; Rienties, Toetenel, \& Bryan, 2015), one major methodological challenge that is often ignored is the granularity of analysis between LD and LA. Most LD activities are conceptualized at a weekly level, or even at a course level. However, the actual behaviour of students occurs on a much finer hour-by-hour or even second-by-second level. It is inevitable that this will lead to discrepancies between intended and actual observed learning behaviours. In other words, there remains a paucity of 
empirical evidence on the magnitude and temporal characteristics of behavioural differences in online environments, and how differences in behavioural patterns of students might vary across different levels of academic performance.

\section{Background}

\subsection{Time Management in Learning}

Time management has been well documented and empirically tested in educational literature as one of the key predictors of academic performance (Broadbent \& Poon, 2015; Claessens, van Eerde, Rutte, \& Roe, 2007; Kim \& Seo, 2015). Time management in the educational setting describes learner effort to make use of their time effectively to achieve certain educational goals within a given time period (Britton \& Tesser, 1991; Macan, Shahani, Dipboye, \& Phillips, 1990). Time management can be view as part of the self-regulated learning framework in which it reflects the planning and goal-setting process (Winne \& Hadwin, 1998). A recent systematic review of 12 studies by Broadbent and Poon (2015) suggested that the strategies of time management, metacognition, effort regulation, and critical thinking were positively correlated with academic performance in the online setting. Numerous studies have confirmed that students who manage their time ineffectively (e.g., procrastinating, cramming for an exam) performed poorly on academic tasks (Cerezo, Esteban, Sánchez-Santillán, \& Núñez, 2017; Kim \& Seo, 2015). For example, Wolters, Won, and Hussain (2017) found that time management is a key aspect of selfregulated learning and can extend our understanding of how students procrastinate on their academic work. Although time management has been extensively studied in the past, there remain three gaps in the literature. First, many studies on time management have relied mainly on self-reported measures (Claessens et al., 2007), such as the time management behaviour scale (TMBS; Macan et al., 1990), the time structure questionnaire (TSQ; Bond \& Feather, 1988), and the time management questionnaire (TMQ; Britton \& Tesser, 1991). As a result, some key aspects of time management (what, when, and for how long students engage) have not been fully understood. Second, several studies have used classroom observational measures of academic engagement, such as scoring systems according to a coding scheme, or an observer recording the time interval of a predefined category of behaviour. However, such classroom observations are time-consuming, limited in scale (i.e., inapplicable to online learning with a large cohort), and subject to observer bias and possible error if the observer is poorly trained. Third, the role of instructional conditions in how students manage their time has received limited attention. From a self-regulated learning perspective, the conditions in which learning takes place influence how learners operate (e.g., time management). Therefore, it is crucial to understand how instructors design their course and its influence on what, when, and for how long students study.

\subsection{Learning Design}

Learning Design, or "Design for Learning" (Goodyear, 2015), is an emerging field since the early 2000s, which aims at developing a descriptive framework to capture teaching and learning activities so that teaching ideas can be shared and reused from one educator to another (Conole, 2012; Dalziel et al., 2016; Lockyer, Bennett, Agostinho, \& Harper, 2009; Maina, Craft, \& Mor, 2015). By explicitly representing the learning activities designed for students, educators are able to reflect on their learning designs and identify potential issues. For instance, in a study of 148 LDs by Toetenel and Rienties (2016b), the introduction of visualizations of initial LDs, accompanied by interactive workshops, helped educators to focus on the development of a range of pedagogical and technological skills and, more importantly, resulted in relatively better "balanced" LDs. Besides reflecting on the LD itself, another important source of feedback is generated from students in their profiles, behaviours, and cognition. In an interview-based study of 30 instructors, Bennett, Agostinho, and Lockyer (2015) identified student-related factors (e.g., cohort profile, learning objectives, feedback from past sessions) as key to influencing how instructors engaged in the design process (together with instructor-related factors and context-related factors).

While feedback from students is vital for the improvement of LD, there are several challenges in terms of the types of feedback and how they are gathered. A first challenge lies in the timing of the feedback, which often takes place after the learning process has finished (e.g., satisfaction survey at end of the module, final exams; Li, Marsh, Rienties, \& Whitelock, 2017; Moskal, Stein, \& Golding, 2016). Not only may these kinds of feedback be subject to self-report bias and sampling bias, they also prevent educators from making in-time interventions as these forms of data are mostly collected at the end of a module. A second challenge is the quality of feedback. Direct interactions with students during class could give important verbal and non-verbal cues of how students react to a certain LD (Biggs \& Tang, 2007; Carless, Salter, Yang, \& Lam, 2011). In blended and online environments, however, reacting to feedback from individual students might be restricted. One potential way forward is to harvest the digital footprints of students in virtual learning environments (VLEs) as proxies of how they engage in learning activities (Ferguson, 2012).

The field of LA has experienced a substantial growth in the last six years since the first LAK conference in Banff, Canada. Included in the wide variety of topics in LA, the alignment between LA and LD has attracted substantial interest (Bakharia et al., 2016; Lockyer \& Dawson, 2011; Nguyen, Rienties et al., 2017b; Rienties et al., 2015). First, the analysis of trace data could equip educators with authentic, fine-grained proxies of how students engage in online learning activities. Second, by capturing 
and visualizing the design of learning activities, the LD approach could provide a pedagogical context to support interpreting and translating LA findings into interventions (Lockyer et al., 2013; Persico \& Pozzi, 2015). A gradual accumulation of empirical evidence has indicated great potential in connecting LA with LD (Gašević, Dawson, Rogers, \& Gasevic, 2016; Nguyen, Rienties, \& Toetenel, 2017a; Nguyen, Rienties et al., 2017b; Nguyen, Rienties, Toetenel, Ferguson, \& Whitelock, 2017; Rienties \& Toetenel, 2016; Rienties et al., 2015). In a large-scale study of 151 modules and their 111,256 students at a distance educational institution, for example, Rienties and Toetenel (2016) revealed significant relations between LD and VLE behaviour, along with student satisfaction and retention. The findings showed that taking the context of LD into account could increase the predictive power of student behaviour by $10-20 \%$. Recently, a longitudinal study of 38 modules by Nguyen, Rienties, Toetenel et al. (2017) indicated that by controlling for the heterogeneity between modules and time periods, LD could explain up to $69 \%$ of the variance in the time spent in the VLE. In addition, Rodríguez-Triana, Martínez-Monés, AsensioPérez, and Dimitriadis (2015) illustrated the potential of orchestrating a monitoring-aware design process, and scripting-aware monitoring process to support instructors in designing computer-supported collaborative learning activities. Considering the instructional conditions is crucial for the development of LA, as it could prevent over- or underestimation of the effect of VLE behaviour on performance (Gašević et al., 2016). Visualizations of student activities or predictive models for at-risk students could offer insights to instructors and instructional designers, but these are not actionable unless the analytics is linked with LD (Tempelaar, Rienties, \& Nguyen, 2017).

\subsection{Temporal Analytics}

Learning occurs over time. The concept of time in education can take many forms, such as a longitudinal study over several years, learning gains across modules, lessons within a course, activities within a lesson, and how learners navigate within each activity. Technological advancement allows researchers to capture fine-grained digital footprints of student behaviour (what, when, and for how long students study). Learning analytics, as a field, has been progressing towards temporal analysis both conceptually and methodologically (Chen, Knight, \& Wise, 2018; Knight, Wise, \& Chen, 2017). As highlighted in the two recent special issues of the Journal of Learning Analytics, there remains some discrepancy between how learning constructs are conceptualized with respect to time and how they are represented in data (Chen et al., 2018; Knight, Wise et al., 2017). Research in time management, by nature, is closely coupled with temporal analytics. For example, Tabuenca, Kalz, Drachsler, and Specht (2015) used a combination of the Validity and Reliability of Time Management Questionnaire (VRTMQ), Online Self-Regulated Learning Questionnaire (OSLQ), and a mobile track tool. The authors found positive effects of tracking time on time management skills. In a similar direction, Manso-Vázquez, Caeiro-Rodríguez, and Llamas-Nistal (2016) proposed a comprehensive solution to use SRL criteria to select and display data focusing on time management.

Another construct that closely relates to time management and temporal analytics is engagement. Time management can be represented by what, when, and for how long students engage in learning activities. While "engagement" is a term used frequently by both researchers and practitioners in education, the conceptualization of engagement and its measurements has not reach a consensus. Engagement is a multidimensional construct ranging from behavioural engagement, emotional engagement, cognitive engagement, and agentic engagement. As highlighted in the special issue of Educational Psychologist, Sinatra, Heddy, and Lombardi (2015) recommended that engagement be considered on a continuum from person-centred to context-centred. Based on this continuum, temporal analytics is placed towards the person-oriented direction. At this end of the continuum, measurements of engagement consist of trace data, or physiological indicators such as eye-tracking, heart rate, etc.

Chen et al. (2018) discussed two features of temporal analytics. The first relates to the passage of time (how long, how often students engage). The second refers to the sequential order in which these activities take place (Molenaar \& Järvelä, 2014). Both features are influenced by students' instructional conditions (i.e., learning design). Instructors often allocate a certain amount of time to each learning activity and organize a series of learning activities in an order that they find optimal. For example, students are guided to read chapter 1 in one hour, followed by some open-ended questions for 20 minutes, and then join the discussion forum for 10 minutes to compare what they have learnt with peers. As a result, learning design is crucial to temporal analytics as it provides reference points to interpret and develop measures for engagement.

\subsection{Research Questions}

When instructors design for learning, they often estimate the workload and corresponding time period for each activity (e.g., take three hours to read chapter 2 in week 2). LD is often embedded in the course syllabus, and acts as a guideline for students to self-regulate their learning process (Biggs \& Tang, 2007; Dalziel, 2015; van Merriënboer, Clark, \& de Croock, 2002). However, learners as agents consciously and perhaps opportunistically make decisions on what, how, and when to engage in a particular range of learning activities (Winne, 2017). While instructors might think that a student will read chapter 2 in week 2 , perhaps some students are already pre-reading materials from week 4, while other students may not have watched the introductory video from week 1 . Therefore, by having a better understanding of how much time students spent on respective learning materials and, more importantly for this study, when in time they studied these learning materials, may enhance our intertemporal understanding of how students make complex study decisions. 
While previous research has shown a strong correlation between the LD and student behaviour in the VLE (Nguyen, Rienties et al., 2017b; Nguyen, Rienties, Toetenel et al., 2017; Rienties \& Toetenel, 2016), the collapse of the time spent on all activities within a module or a week remains a problem for interpretation. For example, not all activities in the VLE are relevant and comparable to the LD (e.g., personal site, library service, accessibility service). Second, the timing of studying has not been fully understood (e.g., studying all materials of week 2 on day 8, 9, or 13). For instance, students could study the learning materials before or after the assigned week. Therefore, this study takes a further step to investigate the time spent on each individual activity and when the students engaged in these activities.

RQ1: To what extent does student timing of engagement align with the instructor's learning design?

Furthermore, many LA studies have indicated that trace behaviours are significantly related to academic performance (Macfadyen \& Dawson, 2010; Tempelaar, Rienties, \& Giesbers, 2015). In addition, extensive research has shown that the ability to plan study time and tasks (time management) was a significant predictor of academic performance (Broadbent \& Poon, 2015; Häfner, Stock, Pinneker, \& Ströhle, 2014). It has been widely acknowledged that students with better learning and self-regulation strategies are more on track with managing their study choices, while students who end up behind the course schedule might struggle to perform effectively over time (Järvelä \& Hadwin, 2013; Vermunt \& Vermetten, 2004). Thus, we hypothesize that high-performing students spend more time studying the learning materials in advance, or in line with the learning design, while low-performing LD students spend more time catching up on their studies.

RQ2: How do different levels of performance and learning design relate to different study patterns?

\section{Method}

\subsection{Setting and Participants}

This study took place at a public distance-education institution in the UK, namely The Open University (OU). The context of the study is a level-2 Environmental Studies module of 30 credits, which corresponds to a 2nd-year course at a regular university. Given our research questions, which focused on comparing instructor assumptions and actual student behaviour, it is crucial to ensure an accurate representation of the actual learning activities. This module was selected because the majority of its learning activities take place in the VLE, in this case, a Moodle platform. This allowed us to capture a more reliable representation of actual online learning behaviour compared to other modules at the OU, whereby learning activities could take place outside of the VLE (e.g., reading PDFs, printed materials, blended learning; Toetenel \& Rienties, 2016a).

There were 268 and 267 registered students in Fall 2015 and Fall 2016 respectively. However, since our research questions focus on exploring the study patterns across differently performing groups (based on final scores), the analysis in this study only took into account the students who completed the course. Thus, the analysis was conducted on 182 from Fall 2015 and 198 students from Fall 2016. In the 2015 implementation, there were more male (61.58\%) than female students. The majority of the students were from the UK $(91.84 \%)$ and of white ethnicity $(88.68 \%)$. In contrast with typical university student profiles, only $13.95 \%$ of the students were under 25 years old, while $44.21 \%$ were $26-35,26.84 \%$ were $36-45,10.26 \%$ were $46-55$, and $4.74 \%$ were over 56 . Most students had a full-time job (63.68\%) or part-time job (15.79\%) while taking the course. The prior educational qualification of students in this module was also diverse, with $28.95 \%$ who had less than A levels, $38.95 \%$ with A-levels or equivalent, and $28.42 \%$ with a higher education qualification. The demographic figures stayed consistent in the 2016 implementation.

The Open University's Human Research Ethics Committee granted ethical approval for this research project. All the students gave implicit consent as they accepted the terms and conditions of registration. Learning analytics conducted in this study is informed by both the "Data Protection Policy" and the "Policy on Ethical Use of Student Data for Learning Analytics." ${ }^{2}$ Since all registered students have given their consent to the OU according to the Data Protection Policy, no further consensus from students was required for this project.

\subsection{Measurement of Learning Design}

The first dataset that captured the LD of the respective module was the result of an institution-wide initiative that helps teams to define their pedagogic approach, choosing and integrating an effective range of media and technologies, and sharing best practices across the university (Cross, Galley, Brasher, \& Weller, 2012). To classify learning activities in an objective and consistent manner, a mapping process was created. Each module goes through a mapping process by a module team, consisting of a LD specialist, a LD manager, and faculty members. First, the learning outcomes specified by the module team are captured by an LD specialist. Each learning activity within the module's weeks, topics, or blocks is categorized under the LD taxonomy (Table 1) and stored in an "activity planner" - a planning and design tool supporting the development, analysis, and sharing of learning designs. Each learning activity can be categorized under one or more categories. For example, activity 1.1 could

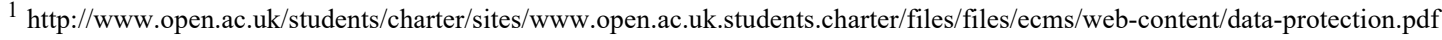

$2 \mathrm{http} / / /$ www.open.ac.uk/students/charter/sites/www.open.ac.uk.students.charter/files/files/ecms/web-content/ethical-use-of-student-data-policy.pdf
} 
consist of 10 minutes of watching video (assimilative) and 20 minutes of open-ended questions (productive). The LD team holds regular meetings to improve the consistency of this mapping process (i.e., several learning designers map the same week of a course and then compare with each other). Next, the LD team manager reviews the resulting module map before the findings are forwarded to the faculty. This provides academics with an opportunity to comment on the data before the status of the design is finalized. This process typically takes 1-3 days for a single module, depending on the number of credits, structure, and quantity of learning resources.

Table 1. Learning Design Taxonomy

\begin{tabular}{|c|c|c|}
\hline & Type of Activity & Examples \\
\hline Assimilative & Attending to information & Read, watch, listen, think about, access \\
\hline Information-seeking & Searching for and processing information & $\begin{array}{l}\text { List, analyze, collate, plot, find, discover, access, } \\
\text { use, gather }\end{array}$ \\
\hline Communication & $\begin{array}{l}\text { Discussing module-related content with at } \\
\text { least one other person (student or tutor) }\end{array}$ & $\begin{array}{l}\text { Communicate, debate, discuss, argue, share, } \\
\text { report, collaborate, present, describe }\end{array}$ \\
\hline Productive & Actively constructing an artefact & $\begin{array}{l}\text { Create, build, make, design, construct, contribute, } \\
\text { complete }\end{array}$ \\
\hline Experiential & Applying learning in a real-world setting & $\begin{array}{l}\text { Practice, apply, mimic, experience, explore, } \\
\text { investigate }\end{array}$ \\
\hline $\begin{array}{l}\text { Interactive } \\
\text { /adaptive }\end{array}$ & Applying learning in a simulated setting & $\begin{array}{l}\text { Explore, experiment, trial, improve, model, } \\
\text { simulate }\end{array}$ \\
\hline Assessment & $\begin{array}{l}\text { All forms of assessment (summative, } \\
\text { formative, and self-assessment) }\end{array}$ & Write, present, report, demonstrate, critique \\
\hline
\end{tabular}

Source: Adapted from Rienties and Toetenel (2016).

The seven types of learning activity were measured in terms of the duration (in hours) that was recommended for each type of activity in a particular week (Figure 1). The purpose of the recommended time spent is to support students in time management in self-regulated learning. The number of credits to be gained determined the total workload of each module, which is the sum of the time allocated for all seven types of learning activity. Each credit is associated with 10 hours of study (so 30 credits $=300 \mathrm{~h}$ and 60 credits $=600 \mathrm{~h}$ ). However, the actual workload can be different and depends on each module's implementation, student characteristics, and student abilities.

In our target module (Figure 2), there are five different types of learning activities, whereby three types of activities (assimilative, productive, assessment) accounted for 91.64\% of the total workload, which were included for comparison purposes. This was due to the difficulty in capturing the actual time spent on finding and handling activities since students could go outside of the VLE to search for information (Knight, Rienties et al., 2017). At the same time, measuring time spent on communication was troublesome, as the compulsory communication activities designed to support certain tasks, and the optional communication activities (e.g., social, café talk) were collapsed under one discussion forum. On average, students in this module were expected to spend 7 hours each week for assimilative, productive, and assessment activities combined. Assimilative activities were allocated on average 4.05 hours per week $(\mathrm{SD}=3.32)$, followed by productive activities $(\mathrm{M}=1.47$, $\mathrm{SD}=1.24)$, and assessment activities $(\mathrm{M}=1.49, \mathrm{SD}=2.88)$. Even though the learning designs remained almost the same between the two semesters, there were two small changes. In particular, there were only two tutor-marked assignments (TMAs) in 2016 instead of three assignments in 2015. Study materials of week 12 and 13 were combined in 2015, while they were separated for each week in 2016. 
Within this document you last viewed: What are systems?

Block 1 Part 1: Reflecting on domestic environmental management

Introduction

In this part, you will begin reflecting upon domestic environmental management. This part will describe further the importance of the domestic context, and give you resources to enable you to make sense of your own domestic environmental management. You will do this through data collection and the introduction of two systems diagram types - systems maps and rich pictures. You will also learn more about the nature of systems and boundaries, and the concept of ecological literacy.

The estimated study time for this week is 10 hours.

Below I have outlined the main activities for this week and the recommended time to be spent studying them.

\begin{tabular}{ll}
\hline Component & Recommended time spent \\
\hline Activity 1.1: perspectives on the nature of systems & 20 minutes \\
\hline Activity 1.2: ecological literacy & 30 minutes \\
\hline Activity 1.3: calculating energy and water usage & 60 minutes \\
\hline Activity 1.4: drawing a rich picture & 45 minutes \\
\hline Activity 1.5: drawing a systems map & 45 minutes \\
\hline Activity 1.6: reflecting on boundary choices & 20 minutes \\
\hline
\end{tabular}

Figure 1. Example of time allocation for each learning activity.

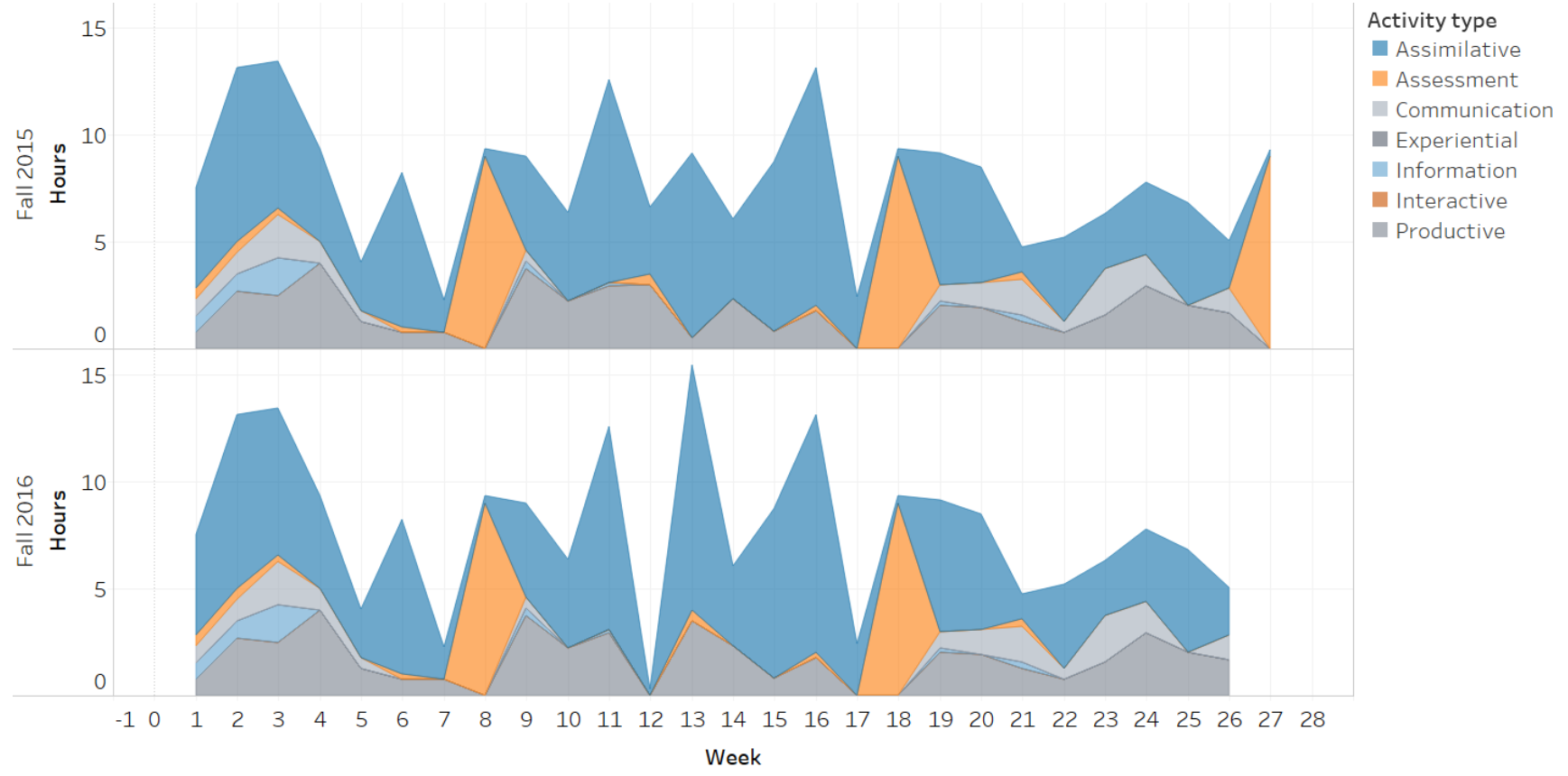

Figure 2. Learning design over two semesters.

\subsection{Measurement of Behavioural Engagement in the VLE}

The second dataset consisted of clickstream data of individual learners from the VLE and was retrieved using SAS Enterprise 9.4. The data were captured from four weeks before the start of the module until four weeks after the end of the module. Learning activities were planned over 30 weeks. Data were gathered in two semesters (Fall 2015 and Fall 2016) in order to validate the findings from two independent implementations. The student behaviour record includes all student VLE activity. In other words, "the spent time" is determined as the time between any two clicks of a student, regardless of the course and the type of VLE activity. Further, not each click can be associated with studying time; for instance, there are clicks related to the downloading of some material, but our information includes the action type connected with the click. Thus, clicks connected to downloads were not included in the time-spent analysis. Nonetheless, we can assume that the time of a click connected to a "view" is associated with the learning time of the study material for which the click is logged.

To compare the LD with the actual student behaviour, time spent on task was calculated as the duration between clicks. As pointed out by previous research (Kovanovic, Gašević, Dawson, Joksimovic, \& Baker, 2016), this metric could be problematic. 
Two factors are involved: 1) the inability to differentiate between active time and non-active time (e.g., students leave the respective web page open and go for a coffee), and 2) the last click of the day is followed by a click the next day), which makes the duration excessively long. Any attempt to set an arbitrary cut-off value would pose a threat in under- or overestimating the actual engagement time.

Taking into account the context and LD of a module could produce a more informed cut-off value. Ideally, this cut-off value should be tailored to the design and context of each individual activity. For example, the cut-off value should be different for a 20-minute activity versus a 1-hour activity. While this study does not fully address the aforementioned problems, it did leverage the design of learning activities (discussion between researchers and designers) to set a cut-off value at 1 hour for all activity (e.g., any activity goes beyond 1 hour will be set as 1 hour).

Since our research question aims at examining to what extent students' timing of engagement aligns with instructor learning design, two types of study patterns were computed to capture how much time a student spent on studying a particular material:

- In advance - material $\mathrm{x}$ assigned to week $\mathrm{t}$ was studied during or before week $\mathrm{t}$

- Catching up and revising - material $\mathrm{x}$ assigned to week $\mathrm{t}$ was studied after week $\mathrm{t}$

In the second research question, we are interested in understanding how these two patterns of learning behaviours varied across three different performance groups, which was measured as the average of all tutor-marked assignments (TMAs) and final exams:

- Failed (average score $<40 \%$ or final exam score $<40 \%$ )

- Passed $(40 \%<$ average score $<75 \%$ and final exam score $>=40 \%)$

- Excellent (average score $>75 \%$ and final exam score $>=40 \%$ )

This categorization builds on previous predictive analytics research (Kuzilek, Hlosta, Herrmannova, Zdrahal, \& Wolff, 2015), which estimated these three categorizations of students across large numbers of students. Of all students who completed the course, there were 52 failed students $(\mathrm{M}=21.2 \%, \mathrm{SD}=16.7 \%), 106$ passed students $(\mathrm{M}=63.6 \%, \mathrm{SD}=7.5 \%)$, and 31 excellent students $(\mathrm{M}=79.5 \%, \mathrm{SD}=3.7 \%)$ in 2015 , and 50 failed students $(\mathrm{M}=25.4 \% \mathrm{SD}=15.9 \%), 119$ passed students $(\mathrm{M}=63.1 \%$, $\mathrm{SD}=8.0 \%)$, and 29 excellent students $(\mathrm{M}=79.7 \%, \mathrm{SD}=3.2 \%)$ in 2016 . We also controlled for the initial level of performance, which was calculated as the average scores of all courses that a student took prior to this course.

\subsection{Data Analysis}

\subsubsection{Visualizations}

To address our first research question, we visualized actual study patterns against the LD over 30 weeks. Second, we visualized the study patterns for respective individual study materials across the excellent, passed, and failed groups. The visualizations were done using Jupyter Notebook and Tableau.

\subsubsection{Mixed-Effect Model}

In order to compare study patterns across the three performance groups over time, we used a multilevel modelling (MLM; or mixed-effect modelling) approach (week $t$ is nested within student $\mathrm{i}$ ). Compared to the traditional repeated measure ANOVA approach, MLM has less stringent assumptions (homoscedasticity, compound symmetry, and sphericity), allows for missing data, tolerates differently spaced waves of data (e.g., due to Christmas breaks, Easter breaks), accounts for autocorrelation of residuals, and allows for nonlinear relations (Quené \& van den Bergh, 2004). First, we started with a random intercept model (weeks are nested within students) as the baseline (not reported here). To address RQ2, we composed two models. The first model (M1) focused on comparing the three groups (baseline = passed students) over time with the time spent on studying "in advance" and "catching up" as the outcomes.

$$
\begin{gathered}
\log \left(1+y_{t i}\right)=\beta_{0 i}+\beta_{1 i} \text { week }_{t}+\beta_{2} \text { Excellent }_{i}+\beta_{3} \text { Fail }_{i}+e_{t i} \\
\beta_{0 i}=\beta_{0}+\mu_{i} \\
\beta_{1 i}=\beta_{1}+\mu_{i}
\end{gathered}
$$

The second model (M2) took into account individual student characteristics (age, gender, education, occupation) and time variant characteristics (the designs of assimilative, productive, and assessment activities). However, since demographics did not improve the overall fit of the model (based on the likelihood ratio test; Quené \& van den Bergh, 2004), they were excluded in the end.

$$
\begin{gathered}
\log \left(1+y_{t i}\right)=\beta_{0 i}+\beta_{1 i} \text { week }_{t}+\beta_{2} \text { Excellent }_{i}+\beta_{3} \text { Fail }_{i}+\beta_{4} \text { Assimilative }_{t}+\beta_{5} \text { Productive }_{t}+ \\
\beta_{6} \text { Assessment }_{t}+e_{t i} \\
\beta_{0 i}=\beta_{0}+\mu_{i} \\
\beta_{1 i}=\beta_{1}+\mu_{i}
\end{gathered}
$$


where outcome y was in advance time or catch-up time Week $\mathrm{t}$ was nested within individual $\mathrm{i}$.

The analysis was done using the lme4 package (Bates, Mächler, Bolker, \& Walker, 2015) in R v.3.3.2 statistical package. Given our moderate sample size and balanced data, p-values were calculated using Type II Wald chi-square tests. A log transformation on the dependent variables (in advance time, and catch-up time) was performed after examining the normality of the residuals. The assumptions of homoscedasticity, multicollinearity, residuals auto-correlation, and non-linearity were checked in all models, which indicated there were no severe violations of these assumptions.

\section{Results}

\subsection{To what extent does student timing of engagement align with the instructor's learning design?}

Figure 3 compares the total time that students spent on study materials in the assigned week against the time recommended by the LD. Compared to the LD (grey line), students in both semesters on average spent much less time studying in the VLE per week $(\mathrm{M}=3.59, \mathrm{SD}=5.29$ for 2015; $\mathrm{M}=3.17, \mathrm{SD}=4.55$ for 2016). In line with previous work (Nguyen, Rienties et al., 2017b; Nguyen, Rienties, Toetenel et al., 2017), the actual study patterns seemed to follow the same trends in the LD. Overall, students in both semesters spent on average more time studying the materials after the assigned week (catching up and revising; $\mathrm{M}=2.14$, $\mathrm{SD}=4.05$ for $2015 ; \mathrm{M}=1.91, \mathrm{SD}=3.48$ for 2016) than before the assigned week (in advance; $\mathrm{M}=1.45, \mathrm{SD}=3.09$ for 2015 ; $\mathrm{M}=1.26, \mathrm{SD}=2.82$ for 2016), except for studying the materials in week 8, week 18, and week 27 (in Fall 2015), which was a TMA.

A closer look at the study patterns across the three different groups (failed, passed, and excellent) is shown in Figure 4a; 4b. Overall, given the same study materials, the "passed" and "excellent" students spent more time studying in advance and catching up than the "failed" students in both semesters (Figure 4a; 4b). In Fall 2015, passed students spent, on average, 1.81 hours $(\mathrm{SD}=3.43)$ per week studying in advance, excellent students spent 2.3 hours $(\mathrm{SD}=3.52)$, and failed students spent 0.22 hours $(\mathrm{SD}=1.05)$. Similar trends in time studying in advance across the three groups occurred in Fall 2016. In Fall 2015, passed and excellent students followed a similar pattern studying in advance. However, in Fall 2016, passed and failed students portrayed a similar pattern for all study materials from week 1 to week 12. From then on, passed students spent more time studying in advance than failed students. Much time was spent on studying in advance in weeks 8, 18, and 27 (for Fall 2015) because of the respective assessments (TMAs) in these weeks (Figure 4a).

Two study materials in weeks 9-10 (part 2.1) and weeks 12-13 (part 2.3) represented red flags of overwhelming workloads, since they were associated with an increase in both studying in advance and catching up (Figure 4a; 4b). In Fall 2015, the passed and excellent students spent much more time catching up on these materials, while the gap was smaller in 2016.

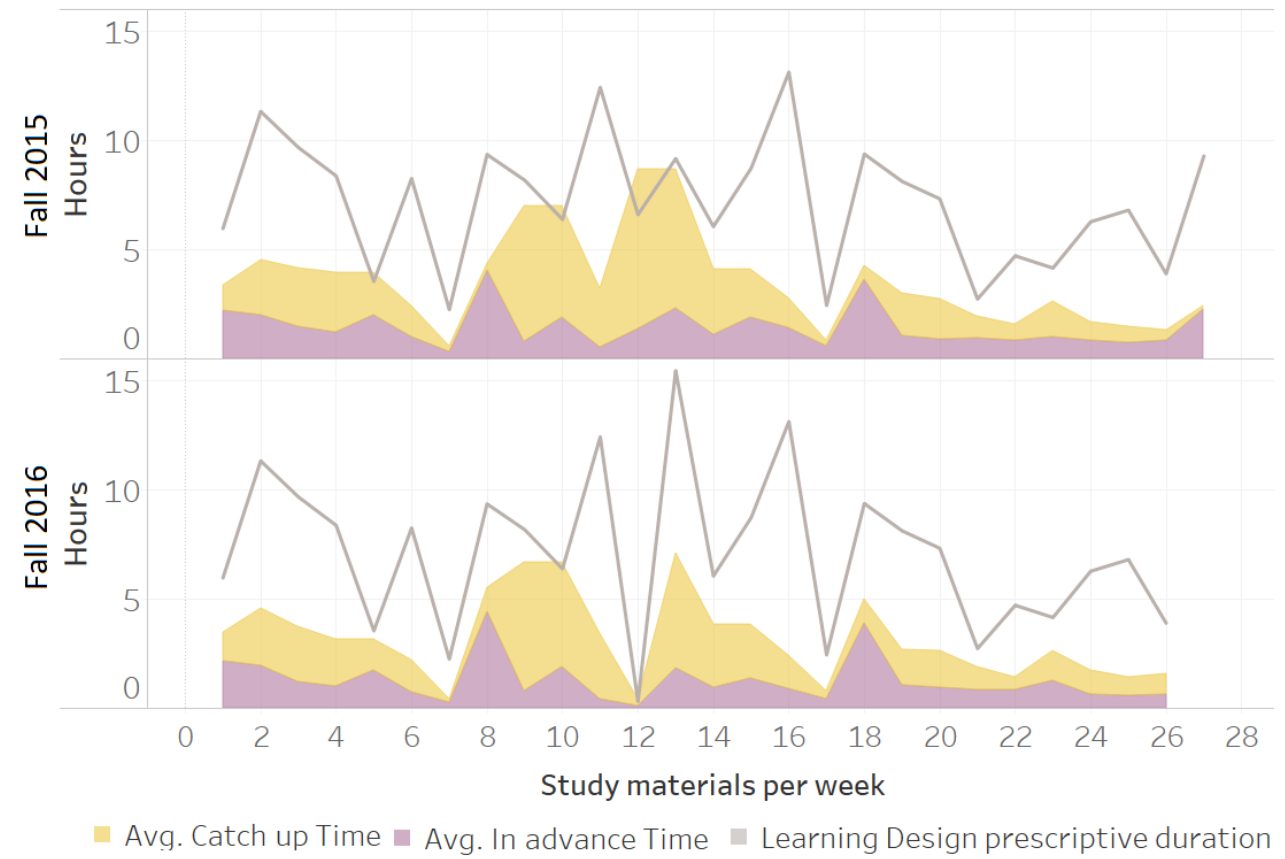

Figure 3. Time spent on study materials per week against the time recommended by instructors.

While excellent and passed students consistently spent more time studying both in advance and catching up than failed students, the relative frequencies revealed a different picture. In both semesters, all three groups of students spent a similar percentage of their time studying in advance in weeks that had a TMA (week 8, 18, 27). However, in Fall 2015 failed students 
spent a higher proportion of their time on catching up activities (61\% on average) than passed $(56 \%)$ and excellent students $(55 \%)$ in almost all weeks (Figure 5).

In Fall 2016, the three groups shared a similar percentage of study time on catching up from week 1 to week 12. After week 12, failed students spent, on average, a much higher proportion of their time on catching up activities compared to passed and excellent students (Figure 5). Towards the end of the course, the gap between failed and passed/excellent students increased considerably (Figure 5).

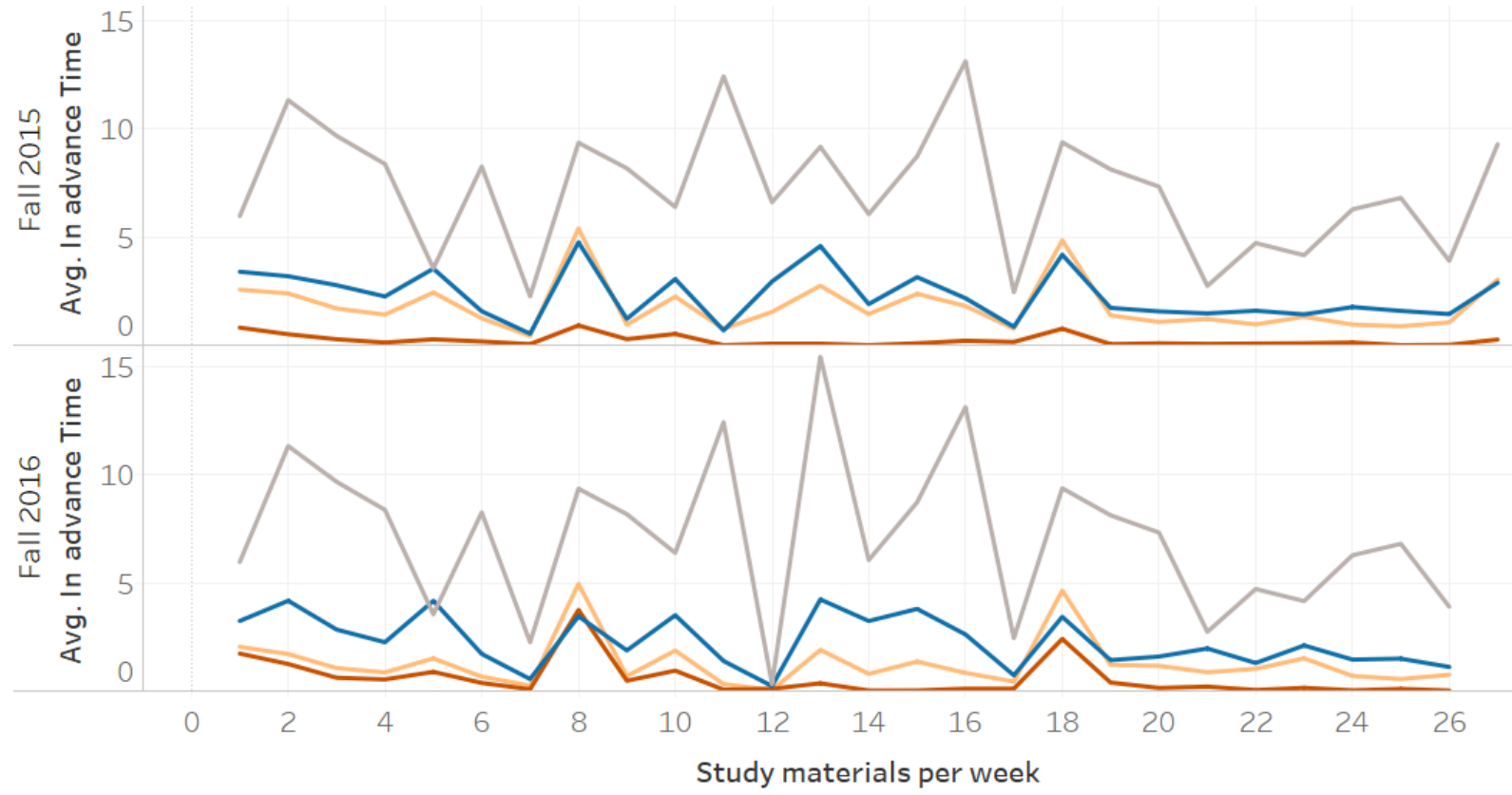

Excellent $\square$ Fail $\square$ Pass $\square$ Learning Design prescriptive duration

Figure 4a. Number of hours spent on studying in advance.

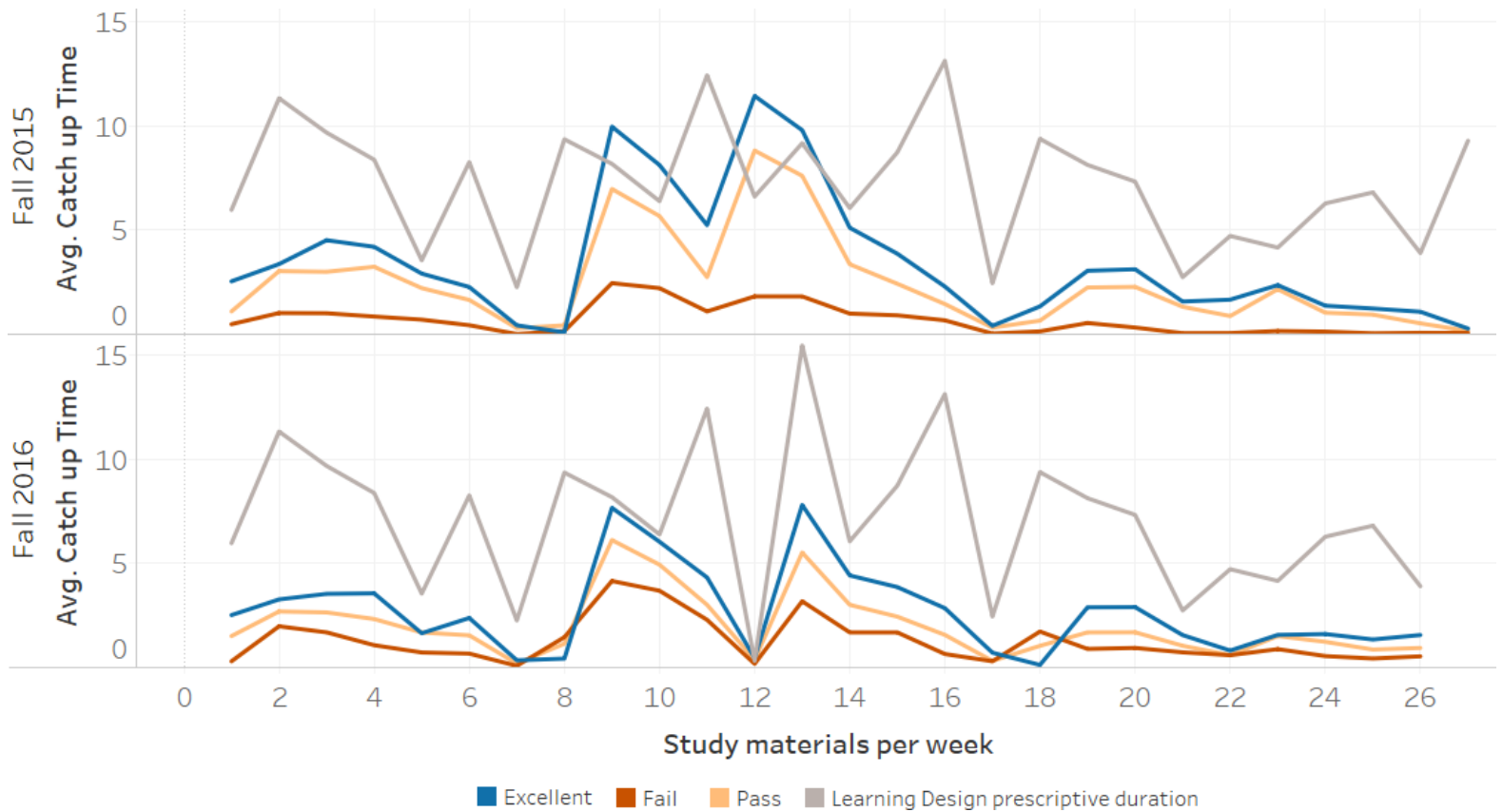

Figure 4b. Number of hours spent on catching up and revising. 


\section{JOURNAL OF LEARNING ANALYTICS}

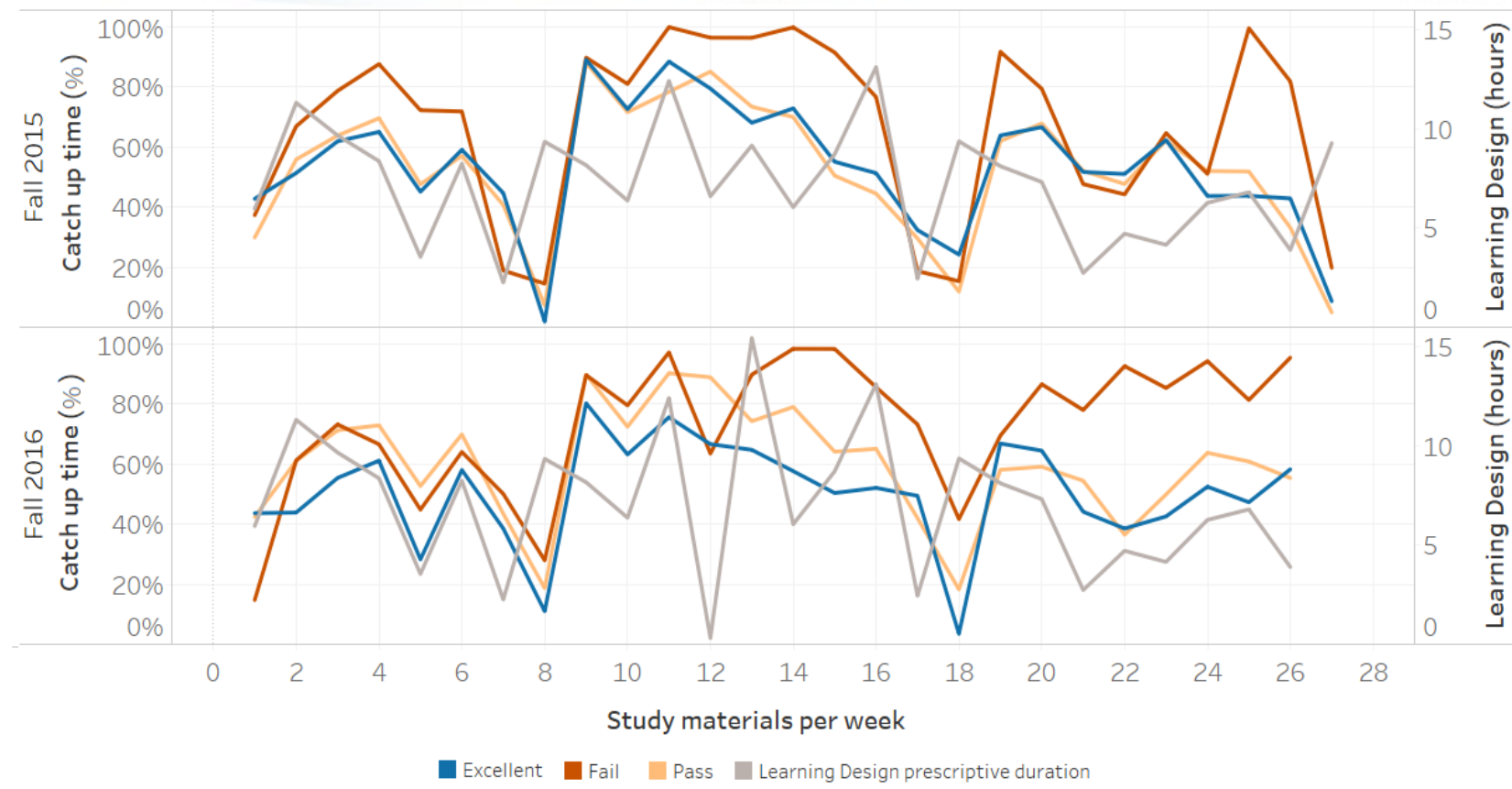

Figure 5. Percentage of time spent on catching up.

\subsection{How do different levels of performance and learning design relate to different study patterns?}

Compared to passed students, failed students spent significantly less time on studying in advance $(B=-0.23, S E=0.03$, $\mathrm{p}<0.001$ ) in 2015, while excellent students did not have any statistically significant difference (Table 2 ). A similar pattern was observed in 2016 for failed students $(B=-0.14, S E=0.03, p<0.001)$ while excellent students spent significantly more time on studying in advance $(\mathrm{B}=0.12, \mathrm{SE}=0.03, \mathrm{p}<0.001)$ (Table 2$)$. Since we performed a log-transformation with the dependent variable, the coefficients should be exponentiated for meaningful interpretations. In other words, compared to passed students, the time spent on studying in advance was $13.06 \%$ lower for failed students and $12.75 \%$ higher for excellent students. After adding the LD (Model 2), the relations between different groups and the time spent on studying in advance remained the same. In 2015, the higher the time designed for assimilative and assessment activities, the higher the time spent on studying in advance. A negative relation was found between productive activities and the time spent on studying in advance. In 2016, the effects of assimilative and productive activities on the time spent studying in advance were no longer significant. In other words, for every one-hour increase in assessment activities, we expect to see a 3-4\% increase in the time spent studying in advance.

In line with our previous visualization (Figure $4 \mathrm{~b}$ ), compared to passed students, failed students in 2015 spent significantly less time on catching up $(B=-0.20, S E=0.03, p<0.001)$, while excellent students spent significantly more time $(B=0.08, S E$ $=0.03, \mathrm{p}<0.001$; Table 3 ). In other words, compared to the passed students, the time spent on catching-up study was $22.14 \%$ lower for the failed students and $8.33 \%$ higher for the excellent students. This catching up could also be regarded as repeating particular learning activities, whereby a vast body of cognitive learning research has found that learning requires repetition. In a similar trend, compared to passed students, the time spent on catching up study in Fall 2016 was 12.75\% lower for failed students and $10.52 \%$ higher for excellent students. All three types of learning activities had a significant relation with time spent on catching up. While the effect of assimilative and assessment activities was relatively small, a one-hour increase in productive activities was associated with a $7.25 \%$ increase in the time spent catching up. 
Table 2. Mixed Effect Model of Time Spent on Studying in Advance

\begin{tabular}{|c|c|c|c|c|c|c|}
\hline & & Fall 2015 & & & Fall 2016 & \\
\hline & $\begin{array}{c}\text { Model } 1 \\
\text { B(SE) }\end{array}$ & $\begin{array}{c}\text { Model } 2 \\
\text { B(SE) }\end{array}$ & $\begin{array}{c}\text { Model } 3 \\
\text { B(SE) }\end{array}$ & $\begin{array}{c}\text { Model } 1 \\
\text { B(SE) }\end{array}$ & $\begin{array}{c}\text { Model } 2 \\
\mathrm{~B}(\mathrm{SE}) \\
\end{array}$ & $\begin{array}{c}\text { Model } 3 \\
\text { B(SE) } \\
\end{array}$ \\
\hline \multicolumn{7}{|l|}{ Fixed } \\
\hline Intercept & $.30(.02)$ & $.30(.03)$ & $\begin{array}{c}.02(.09) \\
-\end{array}$ & $.26(.02)$ & $.20(.02)$ & $\begin{array}{c}-.01(.08) \\
-.00(.00)^{* * *}\end{array}$ \\
\hline Week & $\begin{array}{c}-.00(.00)^{* *} \\
-\end{array}$ & $-.00(.00)^{* * *}$ & $\begin{array}{c}.00(.00)^{* * *} \\
-\end{array}$ & $-.00(.00)^{* * *}$ & $-.00(.00)^{* * *}$ & $-.11(.03)^{* * *}$ \\
\hline Fail & $.23(.03)^{* * *}$ & $-.23(.03)^{* * *}$ & $.19(.03)^{* * *}$ & $-.14(.03)^{* * *}$ & $-.14(.03)^{* * *}$ & \\
\hline Excellent & $.07(.04)$ & $.07(.04)$ & $.04(.04)$ & $.12(.03)^{* * *}$ & $.12(.03)^{* * *}$ & $.11(.04)^{* * *}$ \\
\hline Assimilative & & $.00(.00)^{*}$ & $\begin{array}{c}.00(.00)^{*} \\
-\end{array}$ & & $.00(.00)$ & $.00(.00)$ \\
\hline Productive & & $-.02(.00) * * *$ & $.02(.00)^{* * *}$ & & $.00(.00)$ & $.00(.00)$ \\
\hline $\begin{array}{l}\text { Assessment } \\
\text { Initial Level }\end{array}$ & & $.03(.00) * * *$ & $\begin{array}{l}.03(.00)^{* * *} \\
.00(.00)^{* * *}\end{array}$ & & $.04(.00)^{* * *}$ & $\begin{array}{l}.04(.00)^{* * *} \\
.00(.00)^{* * *}\end{array}$ \\
\hline \multicolumn{7}{|l|}{ Random } \\
\hline Students & $.06(.24)$ & $.06(.24)$ & $.05(.23)$ & $.05(.22)$ & $.05(.23)$ & $.05(.22)$ \\
\hline Week & $.00(.01)$ & $.00(.01)$ & $.00(.01)$ & $.00(.01)$ & $.00(.01)$ & $.00(.01)$ \\
\hline LogLik & -470.8 & -198.5 & -173.4 & -550.2 & -122.1 & -143.3 \\
\hline Obs & 5103 & 5103 & 4968 & 5148 & 5148 & 4966 \\
\hline Students & 189 & 189 & 184 & 198 & 198 & 191 \\
\hline
\end{tabular}

${ }^{*} \mathrm{p}<0.05 ; * * \mathrm{p}<0.01 ; * * * \mathrm{p}<0.001$

Notes: Log-transformation on in-advance time. Baseline $=$ Passed students. Standard errors in parentheses for fixed estimators. Standard deviation in parentheses for random estimators

Table 3. Mixed Effect Model of Time Spent on Catching Up and Revising

\begin{tabular}{|c|c|c|c|c|c|c|}
\hline & & Fall 2015 & & & Fall 2016 & \\
\hline & $\begin{array}{c}\text { Model } 1 \\
\mathrm{~B}(\mathrm{SE}) \\
\end{array}$ & $\begin{array}{c}\text { Model } 2 \\
\mathrm{~B}(\mathrm{SE})\end{array}$ & $\begin{array}{c}\text { Model } 3 \\
\mathrm{~B}(\mathrm{SE}) \\
\end{array}$ & $\begin{array}{c}\text { Model } 1 \\
\mathrm{~B}(\mathrm{SE})\end{array}$ & $\begin{array}{c}\text { Model } 2 \\
\text { B(SE) }\end{array}$ & $\begin{array}{c}\text { Model } 3 \\
\text { B(SE) }\end{array}$ \\
\hline \multicolumn{7}{|l|}{ Fixed } \\
\hline Intercept & $.46(.02)$ & $.23(.03)$ & $.09(.08)$ & $.40(.02)$ & $.15(.02)$ & $.02(.08)$ \\
\hline Week & $-.01(.00)^{* * *}$ & $-.00(.00)^{* * *}$ & $-.00(.00)^{* * *}$ & $-.01(.00)^{* * *}$ & $-.00(.00) * * *$ & $-.00(.00)^{* * *}$ \\
\hline Fail & $-.20(.03)^{* * *}$ & $-.20(.03)^{* * *}$ & $-.18(.03)^{* * *}$ & $-.12(.03)^{* * *}$ & $-.12(.03) * * *$ & $-.11(.03)^{* * *}$ \\
\hline Excellent & $.08(.03)^{* *}$ & $.08(.03)^{* *}$ & $.06(.03)$ & $.10(.03)^{* *}$ & $.10(.03)^{* *}$ & $.09(.04)^{*}$ \\
\hline Assimilative & & $.01(.00)^{* * *}$ & $.01(.00)^{* * *}$ & & $.01(.00)^{* * *}$ & $.01(.00)^{* * *}$ \\
\hline Productive & & $.07(.00)^{* * *}$ & $.08(.00)^{* * *}$ & & $.09(.00)^{* * *}$ & $.09(.00)^{* * *}$ \\
\hline Assessment & & $-.00(.00)^{* *}$ & $-.00(.00)^{*}$ & & $.01(.00) * * *$ & $.01(.00)^{* * *}$ \\
\hline Initial & & & $.00(.00)$ & & & $.00(.00)$ \\
\hline \multicolumn{7}{|l|}{ Level } \\
\hline \multicolumn{7}{|l|}{ Random } \\
\hline Students & $.07(.26)$ & $.07(.27)$ & & $.05(.22)$ & $.05(.22)$ & \\
\hline Week & $.00(.01)$ & $.00(.01)$ & & $.00(.01)$ & $.00(.01)$ & \\
\hline LogLik & -1222.8 & -857.1 & -836.8 & -1183.3 & -711.5 & -711.7 \\
\hline Obs & 5103 & 5103 & 4968 & 5148 & 5148 & 4966 \\
\hline Students & 189 & 189 & 184 & 198 & 198 & 191 \\
\hline
\end{tabular}

${ }^{*} \mathrm{p}<0.05 ; * * \mathrm{p}<0.01 ; * * * \mathrm{p}<0.001$

Notes: Log-transformation on in-advance time. Baseline $=$ Passed students. Standard errors in parentheses for fixed estimators. Standard deviation in parentheses for random estimators 


\section{Discussion}

\subsection{How did students behave compared to the initial learning design?}

In line with previous work (Nguyen, Rienties et al., 2017b; Nguyen, Rienties, Toetenel et al., 2017; Rienties \& Toetenel, 2016), our findings indicated that the way instructors design for learning significantly influenced how students spent time in the VLE. While in general the intended learning design and actual behaviours followed a similar trend over time, there remained substantial discrepancies between what instructors recommended or expected and the actual time spent on respective learning activities by students. In particular, in most weeks students spent less time (nearly half) studying the assigned materials in the VLE compared to the number of hours recommended by instructors. One potential explanation could be that the time spent in the VLE only partially represented the actual time spent overall, since students could study the same materials outside of the VLE (e.g., download PDF files or use other browsers). At the same time, in certain weeks the actual time spent on the assigned materials was equal to or above the time recommended by instructors (i.e., weeks 9,10,12,13). Given that the time spent in the VLE only partially reflected the total time spent on the assigned materials, these discrepancies could signal a major underestimation of the actual workload of the assigned materials. This could potentially discourage and stress out students, given that the majority of students in this course also had a part-time or full-time job, as well as potentially other responsibilities (i.e., family, caring responsibilities).

By comparing and contrasting the assumptions in LD made by instructors with actual student behaviour, LA can act as a reflective resource and provide actionable feedback. For example, instructors could adjust their expected workload of study materials in weeks 9, 10,12, 13 and redistribute the workload more equally. At the same time, instructors could examine whether they overestimated the actual workload in week 16, as the LD allocated 13.13 hours while the actual time spent on the same materials in the VLE was only 2.89 hours on average. However, adjusting the course schedule might not be feasible in certain institutions where instructors are required to provide a detailed schedule in advance for quality-assurance purposes.

Second, our analyses have pointed out that students' actual timing of study engagement could be substantially different from the LD of the assigned week. In particular, most students spent more time studying the materials after the week for which they were assigned. Therefore, given that most students were also working full- or part-time in parallel with their studies, LD should allow for more flexibility in the timing of study. Moreover, instructors should take into account the whole learning process (planning, enacting, and revising) for each learning activity, rather than looking at a learning activity as a single entity occurring only in its assigned week.

One potential implication of our study could be that if students tend to spend more time on catching up a particular learning material, the instructors could check whether the material was clearly explained and provide a quick recap or Q\&A for the material in subsequent weeks. For instance, students across all three groups spent a lot of time catching up the study materials in week 13, which was a case study. Students continuously spent time catching up on this case study for five weeks after week 13. One explanation could be that many study activities after week 13 were based on this case study, therefore students tended to revisit this particular study material. Alternatively, they could revisit this case study as a part of the preparation for their TMA, which took place in week 18. Finally, the high workload or difficulty level in this case study may have required several attempts to complete the task. Either way, instructors can use this information to support their LD practice.

\subsection{How do different levels of performance and learning design relate to different study patterns?}

Not only did students exhibit different study patterns compared to the LD, these patterns also varied significantly across our three groups. Our analysis suggests that excellent students spent the highest amount of time studying both in advance and catching up/revising in the VLE, followed by passed students and then failed students. One obvious interpretation could be that the more effort one puts in, the higher the learning results will be. However, since the time spent in the VLE only partially captured the total effort, another explanation could be that students who studied in the VLE had better results than those who studied on other platforms (e.g., engagement in Facebook's informal learning communities is not tracked by the OU).

Even though this order of engagement intensity across the three groups remained the same in both the in-advance and catching-up study patterns, their relative frequency revealed a different story. Given the same study materials, excellent students spent a large share of their time studying in advance, while failed students spent a large proportion of their study time on catching up. These differences became even more prominent towards the end of the course when $80-100 \%$ of the time spent on the material by failed students was catching-up activities, compared to $40-60 \%$ for passed and excellent students (Figure $4 \mathrm{~b}$ ). Interestingly, for the first 10 weeks, failed, passed, and excellent students spent roughly the same percentage of study time on catching up. An important implication of this could be that instructors should pay careful attention to students with a high percentage of catching up behaviour from week 10 onwards, as that could be a signal of the students falling behind with their study. Alternatively, providing different pacing or study breaks for students might allow "failing" students to catch up, catch their breath, and continue successfully afterwards.

Furthermore, each type of learning activity could significantly influence how much time students study in advance or catching up. For instance, for assessment activities (such as TMAs), all three groups of students spent $80-100 \%$ of their time studying in advance, with the exception of week 18 in 2016 (Figure 4b) when failed students spent on average only $60 \%$ of 
their time studying in advance for assessments. However, for productive activities, students were more likely to delay their action (a one-hour increase in productive activities was associated with a $7.25 \%$ increase in catching up time). Therefore, instructors in this course could re-examine the design of productive activities.

Finally, while the analysis has shown significant relationships between different types of learning activities, different study patterns, and performance by different groups, we also need to keep in mind that learners are agents. Given the same demographics (age, sex, gender, occupation, education) and the same study patterns, different students might still end up with different results. For example, there was 5-6\% random variance across individuals with a standard deviation ranging from $24-$ $30 \%$ (Table 3). In other words, if student A spent 30\% more or less time on studying in advance or catching up than student $\mathrm{B}$, both could still achieve the same outcome (pass the course) in the end.

\section{Conclusion}

This study investigated how students actually study compared to the initial learning design, and how different results (excel, pass, fail) and LD were related to these study patterns. Our analyses were conducted using trace data from the VLE longitudinally over 28 weeks, on 387 students, and replicated over two semesters in 2015 and 2016. Our findings indicate discrepancies between how instructors designed for learning and how students studied in reality. In particular, given the same materials, the time spent in the VLE was on average less than the number of hours recommended by instructors in most weeks. The analysis also pointed out that the timing of study could take place before, during, or after the assigned week. The actual study patterns also varied across the different groups. Excellent students, on average, spent more time studying both in advance and catching up than either passed or failed students. Similarly, the percentage of time spent on catching up activities was higher for failed students compared to passed and excellent students. Finally, different types of learning activities could influence whether students studied in advance or caught up. Our findings also pointed out a large variance between student engagement in the same performance group. While there were some consistent differences in how different groups of students engaged in learning, there was no "golden" recipe for how one should study. This suggested that the "design for the average" approach could easily miss the complexities of how each individual student studies.

From a research perspective, this study contributes to the literature by providing empirical evidence of how and when students study compared to the recommended path designed by instructors. Our findings reinforced the vital position of LD in the context of LA. First, it is important to incorporate LD for methodological purposes, as it can support LA researchers in refining their measurements (i.e., time-on-task estimation). Although this study only partially addressed this issue of measurement, we encourage future scholars to tailor their duration limit of time-on-task to the content and design of individual activity. Second, the inclusion of LD in the analysis could help both researchers and practitioners to better interpret the results. Third, our study showed the importance of temporal characteristics of engagement in LA research, as this could provide a deeper understanding of the learning processes compared to studies with aggregated engagement metrics.

From an instructor perspective, this study makes a step forward in translating LA findings into actionable feedback (Tempelaar et al., 2017). By better understanding how and when students study which materials, and how these behavioural patterns connect with LD, instructors may be in a much better position to reflect on and adjust their teaching practices. By explicitly pointing out which study materials were under- or over-used, instructors can take action. This information can be fed back into a learning analytics dashboard to support instructors and learning designers to track how students progress through each individual study material (on-track or lagging behind). Instructors can use this information to adjust the study workload and rearrange the structure of learning activities accordingly. Our findings also emphasize the need to keep in mind the whole learning process for each learning activity when designing a course, rather than seeing each activity as a single occasion in its assigned week.

From a learner perspective, visualizations of how their peers are studying could act as a practical guideline for students with different learning preferences, supporting them to self-regulate their learning (e.g., plan their study time) more efficiently. For example, if the previous cohort spent a lot of time catching up on a particular week or study material, then a new cohort of students can either start studying the materials earlier or reserve more time for catching up in the following weeks. Moreover, students can make use of their own LA visualizations to keep track of their study plan. For instance, students could set up their own study plans (How much time do I spend on this material? What is my deadline? Etc.) and use LA visualizations of their actual study behaviour to continuously reflect on their study plans (Do I overestimate or underestimate the actual workload? Am I following or falling behind with the course schedule? Etc.).

Finally, readers should keep the limitations of the current study in mind for future research. First, our study was conducted within the context of one online module, which could restrict the generalizability of the study to another context. Our findings can be generalized to most courses at OU and other online courses with a similar design, which are assimilative-oriented and carefully scaffolded. The student population at OU is unique compared to those at traditional universities. We have, on average, an adult population with various educational backgrounds. They often have a full-time or part-time job in parallel to studying. While our first finding might change depending on the context, level of difficulty, and LD of a course, we expect that our 
second finding would remain consistent across different contexts (e.g., high-performing learners engage in a timely manner, and low-performing learners spend a large portion of their time catching up). For comparison purposes, our study only took into account students who completed the course; however, students who withdrew might offer additional insights into the findings. Second, while the LD taxonomy has been developed and implemented at the OU for a long time, it could oversimplify the actual LD (i.e., multiple types of assessment such as formative, summative, self-assessment were collapsed into one category). Keeping the taxonomy concise in order to be able to generalize to other contexts yet, at the same time, detailed enough to separate out different types of learning activities remains a challenging task. Finally, it is important to acknowledge the caveats of using trace data from the VLE. While student behaviour in the VLE has contributed to the increasing accuracy of the predictive algorithm of student performance it does not, of course, capture student behaviour outside of the VLE or offline.

Our study has pointed out some potential issues that instructors could pay attention to. However, further qualitative research is needed (interviews with instructors and students), in order to identify the underlying reasons behind these inconsistencies between the LD and actual student behaviour. Our study has implicitly implied that LD "causes" student engagement. However, the casual relationship between LD and student engagement should be further investigated in future research using quasi-experimental interrupted time-series designs or instrumental variables. Furthermore, while a mixed-effect model allows for dependency between individual observations, some dependencies of residuals between individual observations may exist, or perhaps a non-linear relationship between week and time-on-task. Future studies should therefore consider autocorrelation issues in time-series using autoregressive-moving-average (ARMA) models. Nonetheless, our research clearly points to the need for LA researchers to consider time when modelling LA and LD in particular.

\section{Declaration of conflicting interest}

The authors declare no potential conflicts of interest with respect to the research, authorship, and/or publication of this article.

\section{Acknowledgements}

This work was supported and funded by the Leverhulme Trust, Open World Learning. We would also like to acknowledge the co-supervisors of Quan Nguyen - Prof. Denise Whitelock and Prof. Zdenek Zdrahal. Furthermore, we are grateful for the input from the OU learning design team.

\section{References}

Bakharia, A., Corrin, L., de Barba, P., Kennedy, G., Gašević, D., Mulder, R., . . Lockyer, L. (2016). A conceptual framework linking learning design with learning analytics. Proceedings of the $6^{\text {th }}$ International Conference on Learning Analytics and Knowledge (LAK '16), 25-29 April 2016, Edinburgh, UK (pp. 329-338). New York: ACM. http://dx.doi.org/10.1145/2883851.2883944

Bates, D., Mächler, M., Bolker, B., \& Walker, S. (2015). Fitting linear mixed-effects models using lme4. Journal of Statistical Software, 67(1), 1-48. http://dx.doi.org/10.18637/jss.v067.i01

Bennett, S., Agostinho, S., \& Lockyer, L. (2015). Technology tools to support learning design: Implications derived from an investigation of university teachers' design practices. Computers \& Education, 81, 211-220. http://dx.doi.org/10.1016/j.compedu.2014.10.016

Biggs, J. B., \& Tang, C. (2007). Teaching for quality learning at university, 3 ed. Berkshire, UK: Open University Press.

Bond, M. J., \& Feather, N. (1988). Some correlates of structure and purpose in the use of time. Journal of Personality and Social Psychology, 55(2), 321-329. http://dx.doi.org/10.1037/0022-3514.55.2.321

Britton, B. K., \& Tesser, A. (1991). Effects of time-management practices on college grades. Journal of Educational Psychology, 83(3), 405-410.

Broadbent, J., \& Poon, W. L. (2015). Self-regulated learning strategies and academic achievement in online higher education learning environments: A systematic review. The Internet and Higher Education, 27, 1-13. http://dx.doi.org/https://doi.org/10.1016/j.iheduc.2015.04.007

Carless, D., Salter, D., Yang, M., \& Lam, J. (2011). Developing sustainable feedback practices. Studies in Higher Education, 36(4), 395-407. http://dx.doi.org/10.1080/03075071003642449

Cerezo, R., Esteban, M., Sánchez-Santillán, M., \& Núñez, J. C. (2017). Procrastinating behavior in computer-based learning environments to predict performance: A case study in Moodle. Frontiers in Psychology, 8, 1403. http://dx.doi.org/10.3389/fpsyg.2017.01403

Chen, B., Knight, S., \& Wise, A. F. (2018). Critical issues in designing and implementing temporal analytics. Journal of Learning Analytics, 5(1), 9. http://dx.doi.org/10.18608/jla.2018.53.1

Claessens, B. J. C., van Eerde, W., Rutte, C. G., \& Roe, R. A. (2007). A review of the time management literature. Personnel Review, 36(2), 255-276. http://dx.doi.org/doi:10.1108/00483480710726136

Conole, G. (2012). Designing for learning in an open world (Vol. 4). Springer Science \& Business Media. 
Cross, S., Galley, R., Brasher, A., \& Weller, M. (2012). Final project report of the OULDI-JISC project: Challenge and change in curriculum design process, communities, visualisation and practice. York: JISC. Retrieved from http://www.open.ac.uk/blogs/OULDI/wp-content/uploads/2010/11/OULDI Final Report Final.pdf

Dalziel, J. (2015). Learning design: Conceptualizing a framework for teaching and learning online. New York: Routledge.

Dalziel, J., Conole, G., Wills, S., Walker, S., Bennett, S., Dobozy, E., . . Bower, M. (2016). The Larnaca declaration on learning design. Journal of Interactive Media in Education, 2016(1), 1-24. http://dx.doi.org/10.5334/jime.407

Ferguson, R. (2012). Learning analytics: Drivers, developments and challenges. International Journal of Technology Enhanced Learning, 4(5-6), 304-317. http://dx.doi.org/10.1504/IJTEL.2012.051816

Gašević, D., Dawson, S., Rogers, T., \& Gasevic, D. (2016). Learning analytics should not promote one size fits all: The effects of instructional conditions in predicting academic success. The Internet and Higher Education, $28,68-84$. http://dx.doi.org/10.1016/j.iheduc.2015.10.002

Goodyear, P. (2015). Teaching as design. HERDSA Review of Higher Education, 2, $27-50$.

Häfner, A., Stock, A., Pinneker, L., \& Ströhle, S. (2014). Stress prevention through a time management training intervention: An experimental study. Educational Psychology, 34(3), 403-416. http://dx.doi.org/10.1080/01443410.2013.785065

Järvelä, S., \& Hadwin, A. F. (2013). New frontiers: Regulating learning in CSCL. Educational Psychologist, 48(1), $25-39$. http://dx.doi.org/10.1080/00461520.2012.748006

Kim, K. R., \& Seo, E. H. (2015). The relationship between procrastination and academic performance: A meta-analysis. Personality and Individual Differences, 82, 26-33. http://dx.doi.org/https://doi.org/10.1016/j.paid.2015.02.038

Knight, S., Wise, A. F., \& Chen, B. (2017). Time for change: Why learning analytics needs temporal analysis. Journal of Learning Analytics, 4(3), 11. http://dx.doi.org/10.18608/jla.2017.43.2

Knight, S., Rienties, B., Littleton, K., Mitsui, M., Tempelaar, D., \& Shah, C. (2017). The relationship of (perceived) epistemic cognition to interaction with resources on the internet. Computers in Human Behavior, 73(Supplement C), $507-518$. http://dx.doi.org/https://doi.org/10.1016/j.chb.2017.04.014

Kovanovic, V., Gašević, D., Dawson, S., Joksimovic, S., \& Baker, R. (2016). Does time-on-task estimation matter? Implications on validity of learning analytics findings. Journal of Learning Analytics, 2(3), 81-110. http://dx.doi.org/10.18608/jla.2015.23.6

Kuzilek, J., Hlosta, M., Herrmannova, D., Zdrahal, Z., \& Wolff, A. (2015). OU analyse: Analysing at-risk students at The Open University. Learning Analytics Review, 1-16.

Li, N., Marsh, V., Rienties, B., \& Whitelock, D. (2017). Online learning experiences of new versus continuing learners: A largescale replication study. Assessment \& Evaluation in Higher Education, 42(4), 657-672. http://dx.doi.org/10.1080/02602938.2016.1176989

Lockyer, L., Bennett, S., Agostinho, S., \& Harper, B. (2009). Handbook of research on learning design and learning objects: Issues, applications, and technologies (2 volumes). Hershey, PA: IGI Global. http://dx.doi.org/10.4018/978-1-59904-8611

Lockyer, L., \& Dawson, S. (2011). Learning designs and learning analytics. In P. Long, G. Siemens, G. Conole, \& D. Gašević (Eds.), Proceedings of the $1^{\text {st }}$ International Conference on Learning Analytics and Knowledge (LAK '11), 27 February1 March 2011, Banff, AB, Canada (pp. 153-156). New York: ACM. http://dx.doi.org/10.1145/2090116.2090140

Lockyer, L., Heathcote, E., \& Dawson, S. (2013). Informing pedagogical action: Aligning learning analytics with learning design. American Behavioral Scientist, 57(10), 1439-1459. http://dx.doi.org/10.1177/0002764213479367

Macan, T. H., Shahani, C., Dipboye, R. L., \& Phillips, A. P. (1990). College students' time management: Correlations with academic performance and stress. Journal of Educational Psychology, 82(4), 760.

Macfadyen, L. P., \& Dawson, S. (2010). Mining LMS data to develop an "early warning system" for educators: A proof of concept. Computers \& Education, 54(2), 588-599. http://dx.doi.org/10.1016/j.compedu.2009.09.008

Maina, M., Craft, B., \& Mor, Y. (2015). The art \& science of learning design. Rotterdam, The Netherlands: Sense Publisher. http://dx.doi.org/10.1007/978-94-6300-103-8

Manso-Vázquez, M., Caeiro-Rodríguez, M., \& Llamas-Nistal, M. (2016). Tracking and visualizing time management for selfregulated learners. Proceedings of the 2016 IEEE Frontiers in Education Conference: The Crossroads of Engineering and Business (FIE 2016), 12-15 October 2016, Erie, PA, USA (pp. 1-5). IEEE Computer Society. http://dx.doi.org/10.1109/FIE.2016.7757411

Molenaar, I., \& Järvelä, S. (2014). Sequential and temporal characteristics of self and socially regulated learning. Metacognition and Learning, 9(2), 75-85. http://dx.doi.org/10.1007/s11409-014-9114-2

Mor, Y., Ferguson, R., \& Wasson, B. (2015). Editorial: Learning design, teacher inquiry into student learning and learning analytics: A call for action. British Journal of Educational Technology, 46(2), 221-229. http://dx.doi.org/10.1111/bjet.12273

Moskal, A. C. M., Stein, S. J., \& Golding, C. (2016). Can you increase teacher engagement with evaluation simply by improving the evaluation system? Assessment \& Evaluation in Higher Education, 41(2), $286-300$. http://dx.doi.org/10.1080/02602938.2015.1007838 
Nguyen, Q., Rienties, B., \& Toetenel, L. (2017a). Mixing and matching learning design and learning analytics. Proceedings of the $4^{\text {th }}$ International Conference on Learning and Collaboration Technologies (LCT 2017), held as part of HCI International, 9-14 July 2017, Vancouver, BC, Canada (Part II, pp. 302-316). http://dx.doi.org/10.1007/978-3-319$\underline{58515-424}$

Nguyen, Q., Rienties, B., \& Toetenel, L. (2017b). Unravelling the dynamics of instructional practice: A longitudinal study on learning design and VLE activities. Proceedings of the $7^{\text {th }}$ International Conference on Learning Analytics and Knowledge (LAK '17), 13-17 March 2017, Vancouver, BC, Canada (pp. 168-177). New York: ACM. http://dx.doi.org/10.1145/3027385.3027409

Nguyen, Q., Rienties, B., Toetenel, L., Ferguson, R., \& Whitelock, D. (2017). Examining the designs of computer-based assessment and its impact on student engagement, satisfaction, and pass rates. Computers in Human Behavior, 76, 703714. http://dx.doi.org/10.1016/j.chb.2017.03.028

Persico, D., \& Pozzi, F. (2015). Informing learning design with learning analytics to improve teacher inquiry. British Journal of Educational Technology, 46(2), 230-248. http://dx.doi.org/10.1111/bjet.12207

Quené, H., \& van den Bergh, H. (2004). On multi-level modeling of data from repeated measures designs: A tutorial. Speech Communication, 43(1), 103-121. http://dx.doi.org/https://doi.org/10.1016/j.specom.2004.02.004

Rienties, B., \& Toetenel, L. (2016). The impact of learning design on student behaviour, satisfaction and performance: A crossinstitutional comparison across 151 modules. Computers in Human Behavior, 60, 333-341. http://dx.doi.org/10.1016/j.chb.2016.02.074

Rienties, B., Toetenel, L., \& Bryan, A. (2015). Scaling up learning design: Impact of learning design activities on LMS behavior and performance. Proceedings of the $5^{\text {th }}$ International Conference on Learning Analytics and Knowledge (LAK '15), 1620 March 2015, Poughkeepsie, NY, USA (pp. 315-319). New York: ACM. http://dx.doi.org/10.1145/2723576.2723600

Rodríguez-Triana, M. J., Martínez-Monés, A., Asensio-Pérez, J. I., \& Dimitriadis, Y. (2015). Scripting and monitoring meet each other: Aligning learning analytics and learning design to support teachers in orchestrating CSCL situations. British Journal of Educational Technology, 46(2), 330-343. http://dx.doi.org/10.1111/bjet.12198

Sinatra, G. M., Heddy, B. C., \& Lombardi, D. (2015). The challenges of defining and measuring student engagement in science. Educational Psychologist, 50(1), 1-13. http://dx.doi.org/10.1080/00461520.2014.1002924

Tabuenca, B., Kalz, M., Drachsler, H., \& Specht, M. (2015). Time will tell: The role of mobile learning analytics in selfregulated learning. Computers \& Education, 89, 53-74. http://dx.doi.org/https://doi.org/10.1016/j.compedu.2015.08.004

Tempelaar, D., Rienties, B., \& Giesbers, B. (2015). In search for the most informative data for feedback generation: Learning analytics in a data-rich context. Computers in Human Behavior, 47, 157-167. http://dx.doi.org/10.1016/j.chb.2014.05.038

Tempelaar, D., Rienties, B., \& Nguyen, Q. (2017). Towards actionable learning analytics using dispositions. IEEE Transactions on Learning Technologies, 10(1), 6-16. http://dx.doi.org/10.1109/TLT.2017.2662679

Toetenel, L., \& Rienties, B. (2016a). Analysing 157 learning designs using learning analytic approaches as a means to evaluate the impact of pedagogical decision making. British Journal of Educational Technology, 47(5), 981-992. http://dx.doi.org/10.1111/bjet.12423

Toetenel, L., \& Rienties, B. (2016b). Learning design: Creative design to visualise learning activities. Open Learning: The Journal of Open, Distance and e-learning, 31(3), 233-244. http://dx.doi.org/10.1080/02680513.2016.1213626

van Merriënboer, J. J. G., Clark, R. E., \& de Croock, M. B. M. (2002). Blueprints for complex learning: The 4C/ID-model. Educational Technology Research and Development, 50(2), 39-61. http://dx.doi.org/10.1007/BF02504993

Vermunt, J. D., \& Vermetten, Y. J. (2004). Patterns in student learning: Relationships between learning strategies, conceptions of learning, and learning orientations. Educational Psychology Review, 16(4), 359-384. http://dx.doi.org/10.1007/s10648-004-0005-y

Winne, P. H. (2017). Learning analytics for self-regulated learning. In C. Lang, G. Siemens, A. F. Wise, \& D. Gaševic (Eds.), The Handbook of Learning Analytics (1st ed., pp. 241-249). Alberta, Canada: Society for Learning Analytics Research (SoLAR).

Winne, P. H., \& Hadwin, A. F. (1998). Studying as self-regulated learning. Metacognition in Educational Theory and Practice, 93, 27-30.

Wolters, C. A., Won, S., \& Hussain, M. (2017). Examining the relations of time management and procrastination within a model of self-regulated learning. Metacognition and Learning, 12(3), 381-399. http://dx.doi.org/10.1007/s11409-017-9174-1 